\title{
Carboxylated Nanocrystalline Cellulose from Salix psammophila Prepared by Sulfuric Acid Hydrolysis Combined with 2,2,6,6-tetramethylpiperidine-1-oxyl (TEMPO)-oxidation
}

\author{
Yuan Zhong, ${ }^{\mathrm{a}}$ Xueyi Gao, ${ }^{\mathrm{a},+}$ Wanqi Zhang, ${ }^{\mathrm{b}}$ Xue Wang, ${ }^{\mathrm{c}}$ and Kebing Wang * \\ Salix psammophila (SP) is an important sand plant, and could be utilized \\ to develop high-value products. In this work, SP was used as raw material \\ and cellulose nanocrystals (CNC) were prepared by hydrolysis in $64 \mathrm{wt} \%$ \\ sulfuric acid $\left(\mathrm{H}_{2} \mathrm{SO}_{4}\right)$ solution, and then, TEMPO/NaBr/NaClO system was \\ used to oxidize CNC to obtain TEMPO-oxidation-cellulose nanocrystals \\ (TOCNC). Fourier transform infrared analysis (FTIR) revealed that after \\ oxidation, there were obvious carboxyl functional groups. Scanning \\ electron microscopy (SEM) showed that both CNC and TOCNC were \\ agglomerated. Under atomic force microscope (AFM) and transmission \\ electron microscopy (TEM), CNC and TOCNC presented short rod fibers, \\ average diameters of $23 \mathrm{~nm}$ and $21 \mathrm{~nm}$ and average lengths of $213 \mathrm{~nm}$ \\ and $165 \mathrm{~nm}$, respectively. X-ray photoelectron spectroscopy analysis \\ (XPS) showed that TOCNC generated a new energy spectrum peak at \\ $289.06 \mathrm{eV}$, which was the peak of $\mathrm{C}=\mathrm{O}$ in the carboxyl group. The \\ crystallinity of the CNC and TOCNC were $70.8 \%$ and $26.9 \%$, respectively.
}

DOI: 10.15376/biores.17.1.1373-1384

Keywords: Sand shrub; Sulfuric acid; TEMPO-mediated oxidation; CNC

Contact information: a: College of Science, Inner Mongolia Agriculture University, Hohhot 010018, China; b: College of Materials Science and Art Design, Inner Mongolia Agricultural University, Hohhot 010018, China; c: College of Science, Inner Mongolia Agriculture University, Hohhot 010018, China;

${ }^{+}$These authors contributed equally; *Corresponding author: wkb0803@163.com

\section{INTRODUCTION}

Salix psammophila is a type of sand shrub, which is broad-leaved and has porous wood. It is an important plant for windbreak and sand fixation in arid areas, and one of the characteristic plants for afforestation in sandy land in Inner Mongolia. It has the characteristics of rapid growth, simple reproduction, high survival rate, and resistance to drought (Bao and Zhang 2012). Salix psammophila should be stubbled regularly to keep its growth vitality, thus producing a high amount of waste. The simple incineration of waste S. psammophila not only fails to make rational use of calorific value, but also causes serious environmental pollution such as dust, sulfur oxides, and nitrogen oxides. Therefore, it is particularly important to improve the application of waste sand ash resources and realize the "turning waste into treasure" of waste sand ash resources (Nguyen and Nguyen 2019). Salix psammophila contains $36.9 \%$ cellulose, $35.0 \%$ hemicellulose, $24.8 \%$ lignin, a small amount of ash, tannin, and lipids, etc. (Huang 2014). Due to the high cellulose content in $S$. psammophila, it is often used in pulp and papermaking, chemical raw materials, biomass fuel, and fiberboard. 
Nanocellulose is a fine structure cellulose with a diameter of 1 to $100 \mathrm{~nm}$ obtained by hydrolysis or mechanical treatment of cellulose. Nanocellulose types can be divided into bacterial nanocellulose (BNC) (Ju et al. 2020), cellulose nanocrystalline (CNC) (Shao et al. 2017), and cellulose nanofibrillated (CNF) (Besbes et al. 2011). There are three methods for conventional preparation of nanocellulose. The first method is obtained by pure chemical pretreatment, that is, removing the amorphous zone of cellulose with sulfuric acid, phosphoric acid (Vanderfleet et al. 2018), hydrochloric acid (Shang et al. 2019), and other acids. The second method involves breaking the cellulose itself by mechanical stripping. Representative instruments include an ultrasonic crusher (Jiang et al. 2021), high-pressure homogenizer (Park et al. 2019), and micro-jet nanoscale homogenizer, etc. The third method is to pretreat cellulose through sodium periodate (Sun et al. 2015), TEMPO (De Castro et al. 2018), nitrogen oxide, N-Hydroxyphthalimide (NHPI), and other oxidation systems (Zhou et al. 2014) to change the functional groups of cellulose, thus achieving specific good physical and chemical properties. After such chemical treatments, nanocellulose with different chemical properties can be obtained through mechanical treatment. As a renewable nanomaterial, nanocellulose has been widely used in the fields of medicine, food, papermaking, composite materials, etc. (Kaushik and Singh 2011).

The 2,2,6,6-tetramethylpiperidin-1-oxyl (TEMPO) radical belongs to the nitrosyl radical class and is a type of ring compound with stable nitrogen oxygen radical structure (Isogai et al. 2011). TEMPO is characterized by high oxidation efficiency, mild conditions, and a high degree of selectivity (Bragd et al. 2004). TEMPO can selectively oxidize the primary hydroxyl group at the position $\mathrm{C}_{6}$ of cellulose (Okita et al. 2009), starch (Boccia et al. 2020; Hao et al. 2020), chitin (Fan et al. 2008; Ye et al. 2021), and other polysaccharide long chain macromolecules, turning them into carboxyl groups. Therefore, TEMPO is popular in the field of modification of oxidized polysaccharide compounds (Bragd et al. 2000; Saito and Isogai 2004; Ma et al. 2020).

In the present work, the previously reported isolation of Salix psammophila microcrystalline cellulose (SP-Mic-C), SP-Mic-C was used as raw material to prepare CNC by hydrolyzed with sulfuric acid. Then, TOCNC was prepared by TEMPO/ $\mathrm{NaBr} / \mathrm{NaClO}$ mediated oxidation, and the products were characterized with a view to make subsequent aerogel and hydrogel materials on the basis of this material.

\section{EXPERIMENTAL}

\section{Materials and Methods}

Materials and reagent

Salix psammophila specimens were collected from Kabuki Desert of Ordos, China. Samples were cleaned with water, dried, and crushed; 100 to 120 mesh powder was measured for reserve. The following materials and reagents were used in the experiment: nitric acid $\left(\mathrm{HNO}_{3}\right)$, hydrochloric acid $(\mathrm{HCl})$, sulfuric acid $\left(\mathrm{H}_{2} \mathrm{SO}_{4}\right)$ (Sinopharm Chemical Reagents Co., Ltd., Beijing, China); sodium chlorite $\left(\mathrm{NaClO}_{2}\right)$ 80\% TEMPO, sodium bromide (NaBr) (McLean Chemical Reagents Ltd., Shanghai, China); anhydrous ethanol $\left(\mathrm{C}_{2} \mathrm{H}_{5} \mathrm{OH}\right)$, sodium hypochlorite $(\mathrm{NaClO})$, sodium hydroxide $(\mathrm{NaOH})$ (Tianjin Kemao Chemical Reagent Co., Ltd., Tianjing, China); glacial acetic acid $\left(\mathrm{CH}_{3} \mathrm{COOH}\right)$ (Tianjin Fuchen Chemical Reagent Co., Ltd., Tianjing, China); potassium hydroxide(KOH) (Tianjin Jinhuitai Subchemical Reagent Co., Ltd., Tianjing, China). The above drugs were analytically pure. 
Preparation of S. psammophila microcrystalline cellulose

The extraction of cellulose from Salix microcrystalline was based on the method described in a previous paper (Zhong et al. 2020). $10 \mathrm{~g} \mathrm{~S}$. psammophila was weighed and heated in distilled water at 1:60 g/mL for $1 \mathrm{~h}$ at $80{ }^{\circ} \mathrm{C}$. Impurities and some water-soluble components were removed by filtration, and the yield was $87 \%$. The $\mathrm{HNO}_{3}-\mathrm{C}_{2} \mathrm{H}_{5} \mathrm{OH}$ solution $(1: 3 \mathrm{~V} / \mathrm{V}, 1: 43 \mathrm{~g} / \mathrm{mL})$ was weighed and placed in a three-necked flask, condensed, and refluxed at $90^{\circ} \mathrm{C}$. After the sample was removed, it was washed to neutral with distilled water and anhydrous ethanol and dried at $105^{\circ} \mathrm{C}$ with constant weight. After drying, it was added into $7.5 \mathrm{wt} \% \mathrm{NaClO}(1: 20 \mathrm{~g} / \mathrm{mL})$, adjusted to $\mathrm{pH}$ of 3 to 4 with $\mathrm{CH}_{3} \mathrm{COOH}$, reacted at $75{ }^{\circ} \mathrm{C}$ for $3 \mathrm{~h}$, washed with distilled water and anhydrous ethanol to neutral, and dried at $60{ }^{\circ} \mathrm{C}$ to constant weight. The bleached samples were then placed in $10 \% \mathrm{KOH}(1: 20 \mathrm{~g} / \mathrm{mL})$ solution, magnetically stirred at $75{ }^{\circ} \mathrm{C}$ for $2 \mathrm{~h}$, washed to neutral, and dried to constant weight at $60{ }^{\circ} \mathrm{C}$. Finally, $8 \mathrm{wt} \% \mathrm{HCl}$ solution $(1: 20 \mathrm{~g} / \mathrm{mL})$ was hydrolyzed at $90{ }^{\circ} \mathrm{C}$ for 1.5 $\mathrm{h}$. The product was successively washed with distilled water and anhydrous ethanol to neutral. After drying, the sample was named SP-Mic-C.

Preparation of cellulose nanocrystalline by sulfuric acid hydrolysis

$1 \mathrm{~g}$ of SP-Mic-C was accurately weighed, and was put into a $20 \mathrm{~mL}$ conical flask, with $10 \mathrm{~mL}$ of $64 \mathrm{wt} \% \mathrm{H}_{2} \mathrm{SO}_{4}$ solution, and was stirred at $45{ }^{\circ} \mathrm{C}$ for $45 \mathrm{~min}$. Then, the solution was diluted with $900 \mathrm{~mL}$ distilled water. It was allowed to stand overnight, and then the supernatant was poured out. A certain amount of distilled water was added again, and this process was repeated 2 to 3 times. A dialysis bag (8000 to $14000 \mathrm{MW}$ ) was used for dialysis until the $\mathrm{pH}$ was nearly neutral (Ping and Hsieh 2012). The sample was named CNC after freeze-drying, and the yield was about $73.9 \%$.

Preparation of TEMPO-oxidation-cellulose nanocrystalline by TEMPO oxidation

$1 \mathrm{~g}$ of CNC was added to the flask, $100 \mathrm{~mL}$ of water was added, and $0.032 \mathrm{~g}$ TEMPO and $0.603 \mathrm{~g} \mathrm{NaBr}$ were then added.

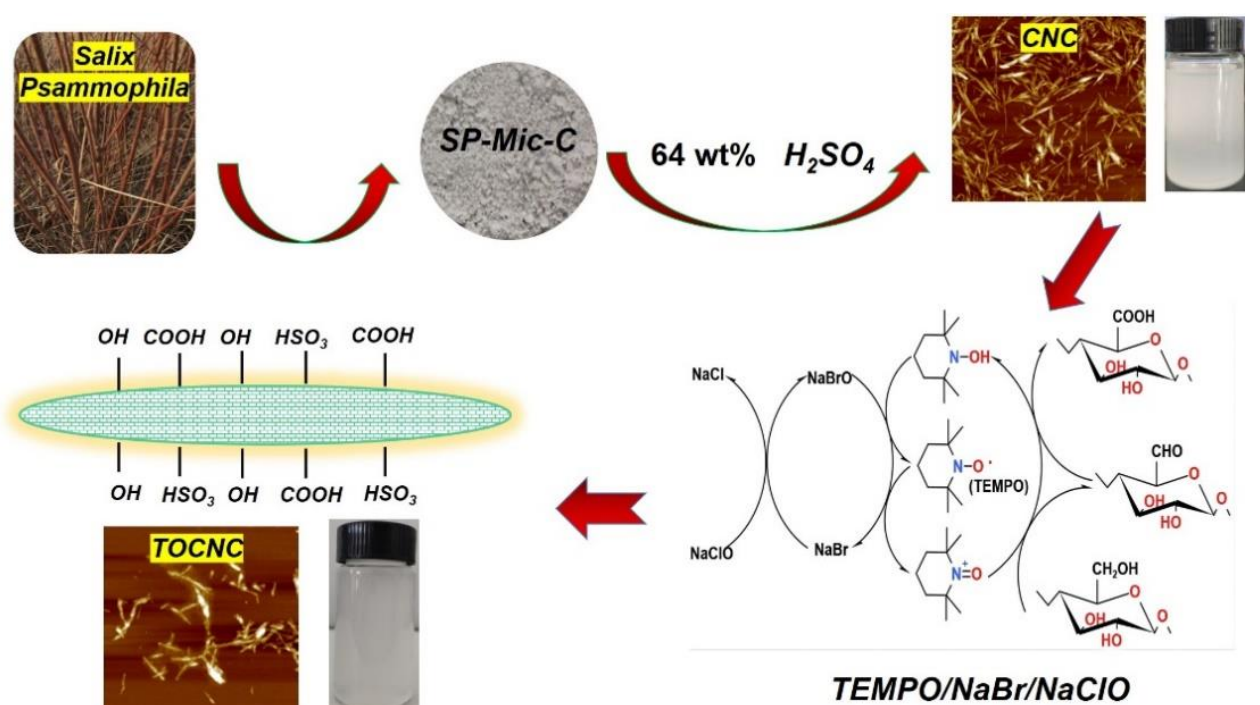

Fig. 1. TOCNC preparation process and mechanism diagram 
After stirring at $60{ }^{\circ} \mathrm{C}$ for $30 \mathrm{~min}, 20 \mathrm{~mL} \mathrm{NaClO}$ solution (10 wt $\%$ ) was added, and $0.5 \mathrm{M} \mathrm{NaOH}$ solution was used to adjust the $\mathrm{pH}$ of the solution to 10.0 10.5 until the end of the reaction. Anhydrous ethanol $(20 \mathrm{~mL})$ was used to quench the reaction. The solution was dialyzed to neutral and freeze-dried. The sample was named TOCNC with a yield of approximately $21.7 \%$. The TOCNC preparation process is shown in Fig. 1.

\section{Analysis Methods}

Scanning electron microscopy (SEM)

Scanning electron microscopy (SEM) (Hitachi 4800; Hitachi Limited, Tokyo, Japan) was used to observe the changes of the sample surface during the process from raw material to cellulose. The scanning electron microscope (SEM) was operated at an accelerating voltage of $10 \mathrm{kV}$. A small number of samples was placed on conductive adhesive. Then they were gold sprayed (Small ion sputtering instrument; Beijing Zhongke Instrument Co., Ltd., Beijing, China), and their morphology was observed.

\section{Transmission electron microscopy (TEM)}

For TEM, a FEI Tecnai S-200kV Twin field emission high resolution transmission electron microscope was used (Thermo Fisher Scientific, Waltham, MA, USA). The sample was diluted with anhydrous ethanol, dried in copper mesh and tested.

\section{Atomic force microscope analysis (AFM)}

The test was performed with a Bruker atomic force microscope (Dimension Icon; Bruker Corporation, Madison, WI, USA). A certain amount of nanocellulose was diluted with distilled water and stirred evenly. A drop of nanocellulose suspended liquid was placed on the mica sheet, and the sample with a range of $2 \mu \mathrm{m} \times 2 \mu \mathrm{m}$. Photoshop CC 2019 (Adobe Systems Incorporated, 2019, State of California, USA) was used to measure and analyze the diameter and length of the nanocellulose.

\section{Fourier transform infrared spectroscopy (FTIR)}

The FTIR spectra were measured using a Perkin Elmer 65 (Perkin Elmer Instruments Co., Ltd., Waltham, MA, USA). The experimental parameters included a range of 4000 to $600 \mathrm{~cm}^{-1}$. The cumulative number of scans was 32, and the resolution was $1 \mathrm{~cm}^{-1}$.

\section{$X$-ray photoelectron spectroscopy (XPS)}

Elemental analysis of the material surface was performed with the Thermo Scientific Escalab 250XI (Thermo Fisher Technologies, Waltham, MA, USA) photoelectron spectrometer, and the radiation source was Al-K $\alpha$.

\section{Thermo gravimetric analysis (TGA)}

The TGA experiments were performed on an HCT-1 integrated thermal analyser (Beijing Hengjiu Scientific Instrument Factory, Beijing, China). The samples were analysed in $\mathrm{N}_{2}$ atmosphere with a pressure of $0.3 \mathrm{MPa}$, a flow rate of $20 \mathrm{~mL} / \mathrm{min}$, a heating rate of $10^{\circ} \mathrm{C} / \mathrm{min}$, and a temperature range of 25 to approximately $800{ }^{\circ} \mathrm{C}$.

$X$-ray diffraction $(X R D)$

Tests were run in an X-ray diffractometer (Empyrean Alpha-1, Shanghai SIBG Instrument System Co., Ltd., Shanghai, China). Test conditions were the following: $\mathrm{Cu}$ Ka 
radiation at a generator voltage of $40 \mathrm{kV}$ and current of $40 \mathrm{~mA}$; radiation angle for $2 \theta=5^{\circ}$ to approximately $80^{\circ}$, with a step size of $0.017^{\circ}$ and a count time of $4.5 \mathrm{~min}$. The crystallinity index of samples was calculated by the Segal equation (Segal et al. 1959), listed here as Eq. 1,

$$
\mathrm{CrI}=\left(I_{2}-I_{1}\right) / I_{2} \times 100 \%
$$

where $\mathrm{CrI}$ is the crystallinity index $(\%), I_{2}$ is the crystalline peak intensity around $2 \theta=20^{\circ}$, and $I_{1}$ is the amorphous intensity of the background scattered measure around $2 \theta=18^{\circ}$.

\section{RESULTS AND DISCUSSION}

\section{The Sample Appearance}

Figure 2 shows the nanocellulose prepared in this study. The CNC obtained after $\mathrm{H}_{2} \mathrm{SO}_{4}$ treatment was milky white. In addition, both nanocellulose solutions were pale blue at very low concentrations, and the dilute suspensions remained stable within a month.
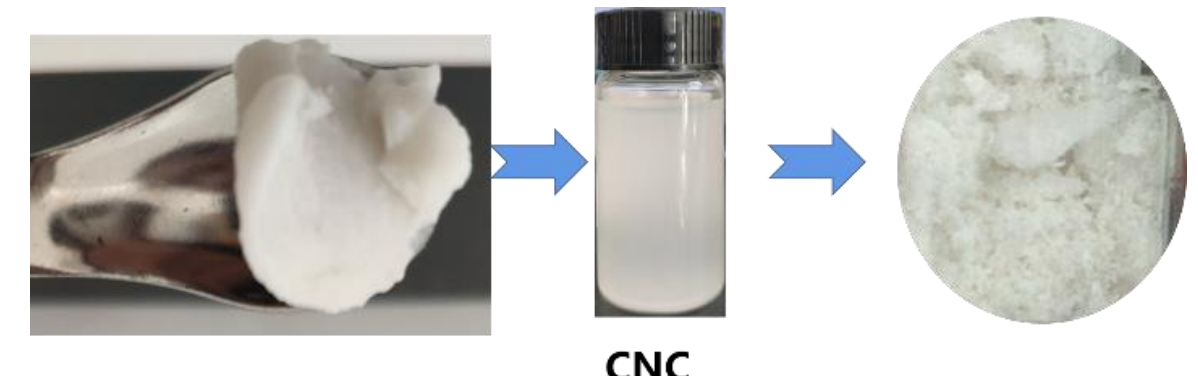

CNC
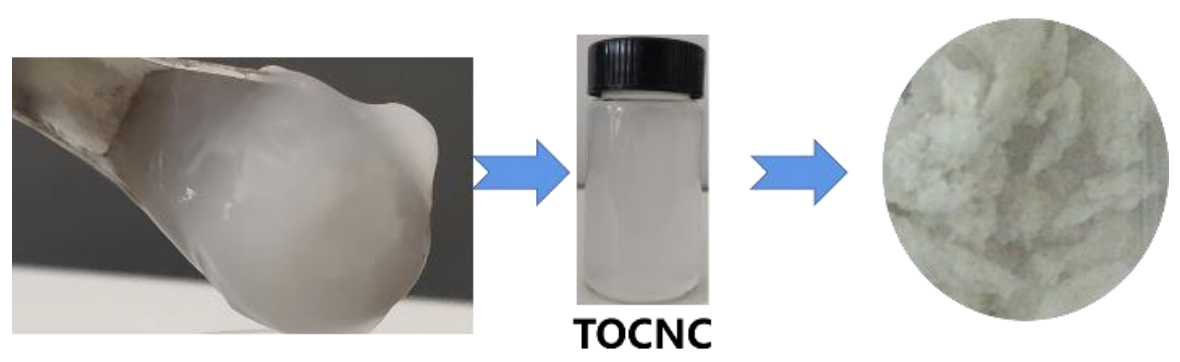

Fig. 2. Morphology (Left, after centrifugal; Right, after freeze drying) of CNC and TOCNC

\section{Scanning Electron Microscopy (SEM)}

The SP-Mic-C, CNC, and TOCNC SEM images are shown in Fig. 3. As can be seen from Fig. 3a, SP-Mic-C had a long rod-like structure. SP-Mic-C had been hydrolyzed by $\mathrm{H}_{2} \mathrm{SO}_{4}$. The relatively uniform size of particles of $\mathrm{CNC}$ is attributed to the rapid hydrolysis of the amorphous cellulose regions by the concentrated sulfuric acid (Fig. 3b). Based on the images shown in the micrographs, the CNC particles appear to have been reunited into a layered structure, such that it was no longer possible to distinguish between single nanorods. Compared with CNC, TOCNC (Fig. 3c) showed a smoother layer surface and exhibited smaller flocs and fault. After TEMPO oxidation treatment of CNC, more hydroxyl and carboxyl groups on the surface of the oxidized nanocellulose enable it to absorb water and swell, and the bloated nanocellulose will form more hydrogen bonds after freeze-drying treatment, resulting in a denser structure. 

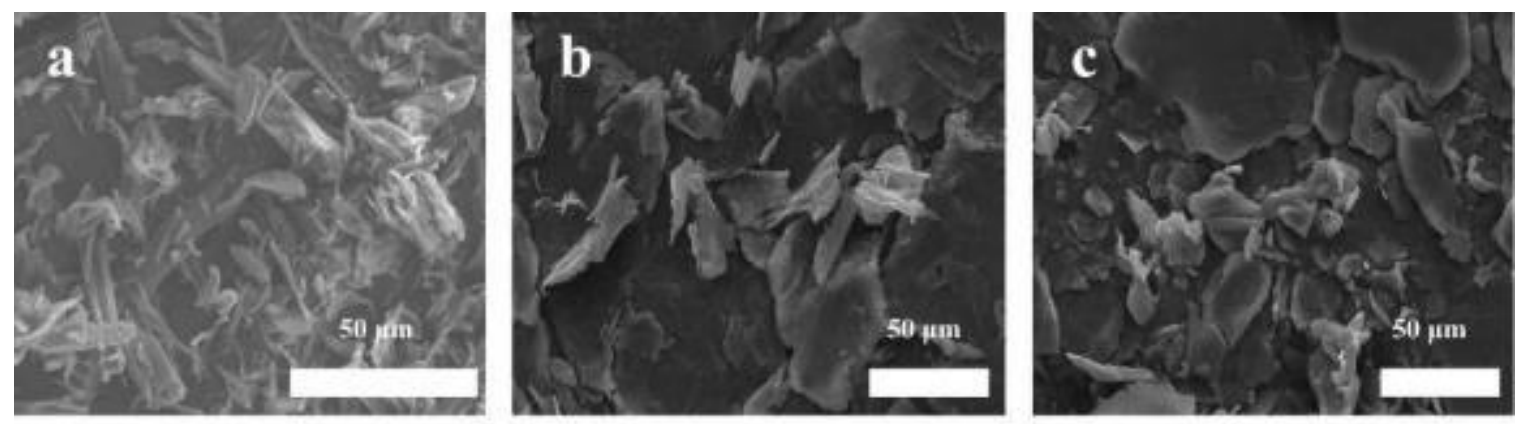

Fig. 3. SEM images of SP-Mic-C (a), CNC (b), and TOCNC (c)

\section{FTIR Analysis}

Figure 4(a) shows the FTIR spectra of SP-Mic-C, CNC, and TOCNC. The wide absorption band at $3340 \mathrm{~cm}^{-1}$ is the stretching vibration peak of $-\mathrm{OH}$. The peak of $-\mathrm{CH}_{3}$ near 2900 to $2971 \mathrm{~cm}^{-1}$ is the C-H stretching vibration (Kumar et al. 2019); $1600 \mathrm{~cm}^{-1}$ is the asymmetric contraction vibration of $-\mathrm{COO}^{-}$(Mendoza et al. 2019), which does not appear in the SP-Mic-C and CNC. However, after TEMPO oxidation treatment, the TOCNC exhibited carboxyl functional groups, indicating that the preparation of TOCNC was successful. Near $1434 \mathrm{~cm}^{-1}$ is the type for $-\mathrm{CH}_{2}$ bending vibration peak (Luo and Wang 2018). This indicates that samples remained as the cellulose I type crystal type, and there was no structural change; $1032 \mathrm{~cm}^{-1}$ is the $\mathrm{C}-\mathrm{O}$ stretching vibration peak of cellulose. It also is the characteristic absorption peak of cellulose (Yang et al. 2015).
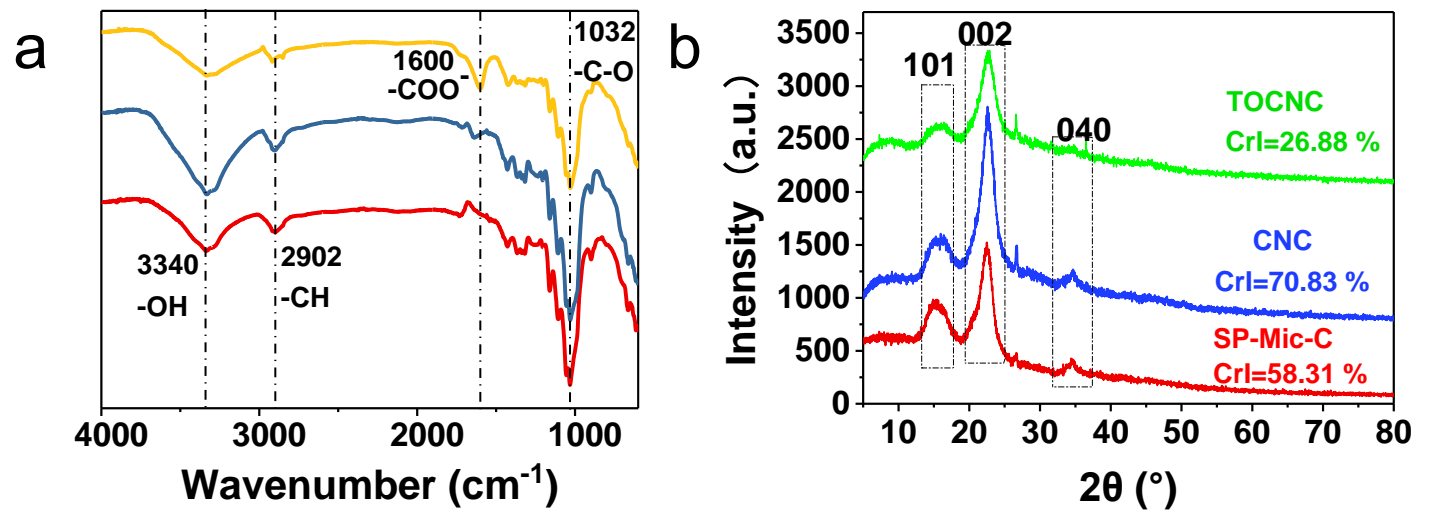

Fig. 4. FTIR analysis (a) and XRD patterns (b) of SP-Mic-C, CNC, and TOCNC

\section{XRD Analysis}

Figure 4(b) shows the XRD diagram for SP-Mic-C, CNC, and TOCNC; the peaks at $2 \theta=16^{\circ}, 22^{\circ}$, and $34^{\circ}$ were associated with the (101), (002), and (040) crystal planes for the cellulose type I crystalline structure (Yan et al. 2019). After the $\mathrm{H}_{2} \mathrm{SO}_{4}$ hydrolysis, CNC crystallinity of 70.8\% was far higher than SP-Mic-C, 58.3\%. After TEMPO oxidation, the crystallinity of TOCNC dropped sharply to $26.9 \%$. This can be attributed to $\beta$ elimination reaction and the degradation reaction. (Henriksson et al. 2007).

\section{AFM Analysis}

The atomic force microscope is an instrument for imaging samples using optical lever technology. The method has a good resolution for examination of nanoscale materials. Figure $5(\mathrm{a}, \mathrm{b})$ is the atomic force microscope diagram of $\mathrm{CNC}$ and TOCNC, 
from which it can be seen that both nanocellulose are short rods, which is consistent with the effect shown by TEM, and the image is clearer. From Fig. 5 (a1, a2, b1, b2), which shows length and width distribution of CNC and TOCNC, the average diameter of nanocellulose decreased from $23 \mathrm{~nm}$ to $21 \mathrm{~nm}$, and the average length decreased from 213 $\mathrm{nm}$ to $165 \mathrm{~nm}$. The experimental data demonstrates that preparation of the TEMPOoxidized cellulose involved a certain extent of degradation, and the introduction of carboxyl groups also improved the dispersion of the particles.
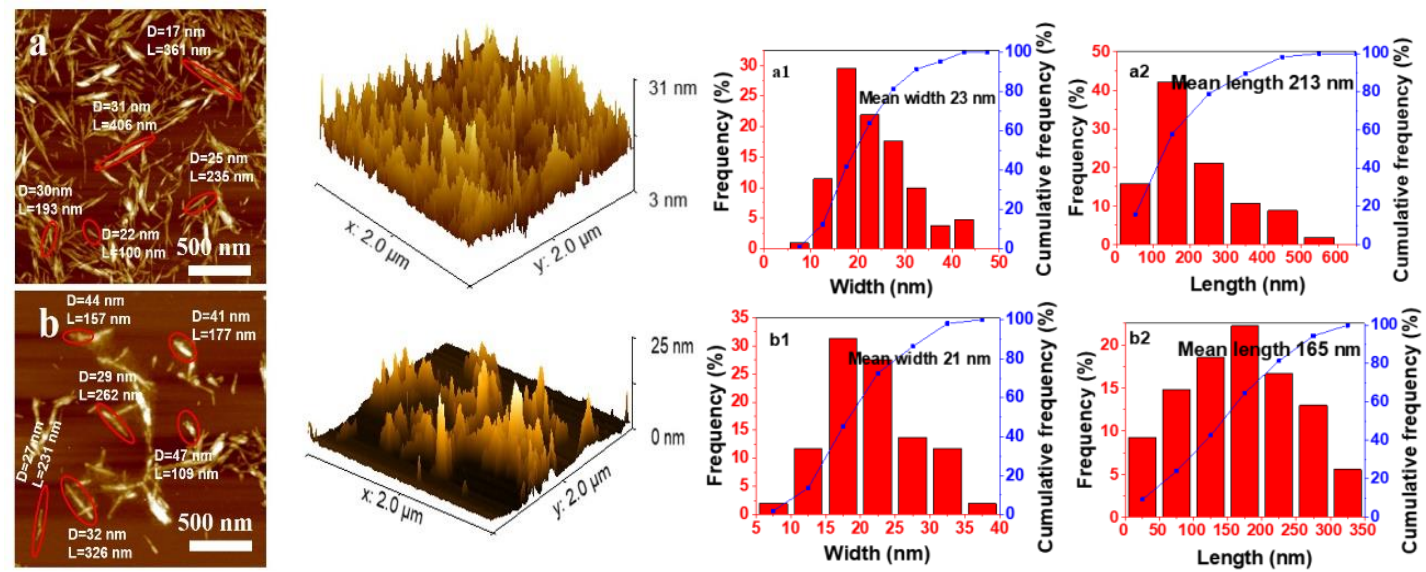

Fig. 5. AFM images of CNC (a) and TOCNC (b): width and Length distribution of CNC (a1, a2) and TOCNC (b1, b2)

\section{TEM Analysis}

The TEM method directly examines thin samples with the help of electrons to form an image. It can be seen from Fig. 6 that the $\mathrm{CNC}$ had a fine rod-like structure, and after TEMPO-mediated treatment, the diameter and length of TOCNC were slightly lower than those of CNC.

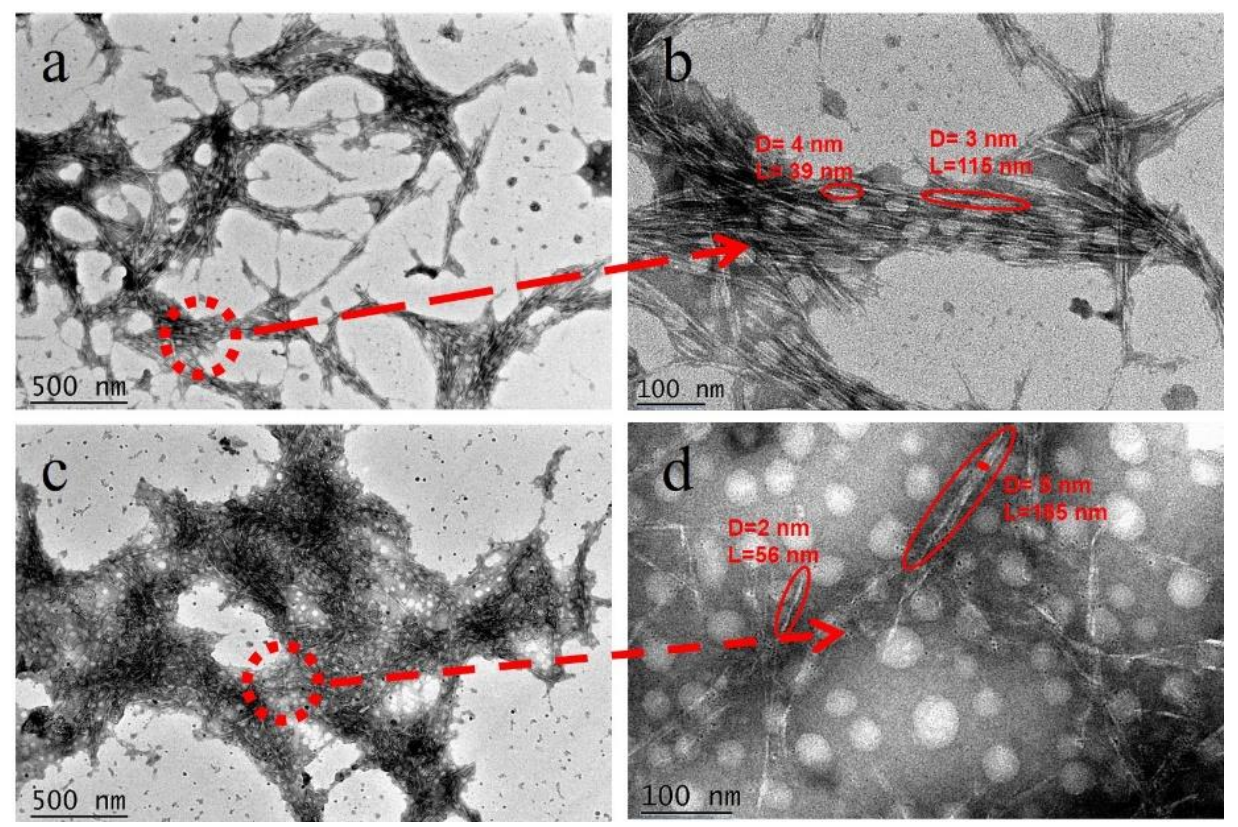

Fig. 6. TEM images of CNC (a, b) and TOCNC (c, d) 
Both $\mathrm{CNC}$ and TOCNC were subject to relatively obvious agglomeration phenomena. Because the surface of nanocellulose is rich in hydroxyl groups, it is easy to form hydrogen bonds. The hydrogen bonds between cellulose and van der Waals forces cause the formation of nanocellulose fiber bundle agglomerations.

\section{TGA Analysis}

The SP-Mic-C, CNC, and TOCNC TG (Fig. 7a) and DTG (Fig. 7b) analysis diagram is shown in Fig. 7. Moisture becomes volatilized usually within the range 50 to $150{ }^{\circ} \mathrm{C}$ for the samples. The $\mathrm{CNC}$ exhibited the largest thermal decomposition temperature of $263{ }^{\circ} \mathrm{C}$, which was lower than the TOCNC maximum thermal decomposition temperature of $296{ }^{\circ} \mathrm{C}$. The maximum thermal decomposition temperature of SP-Mic-C was $354^{\circ} \mathrm{C}$. Thus, the TOCNF decomposition was nearly $70^{\circ} \mathrm{C}$ lower than that of SP-MicC. There are two reasons for this. First, this was because the two kinds of nanocellulose have different particle sizes, surface and degree of polymerization, which leads them to have greater exposure of surface area; Second, it is caused by the introduction of sulfonic acid groups and acid hydrolysis and reduction of the degree of polymerization of cellulose chains (Rosa et al. 2010).
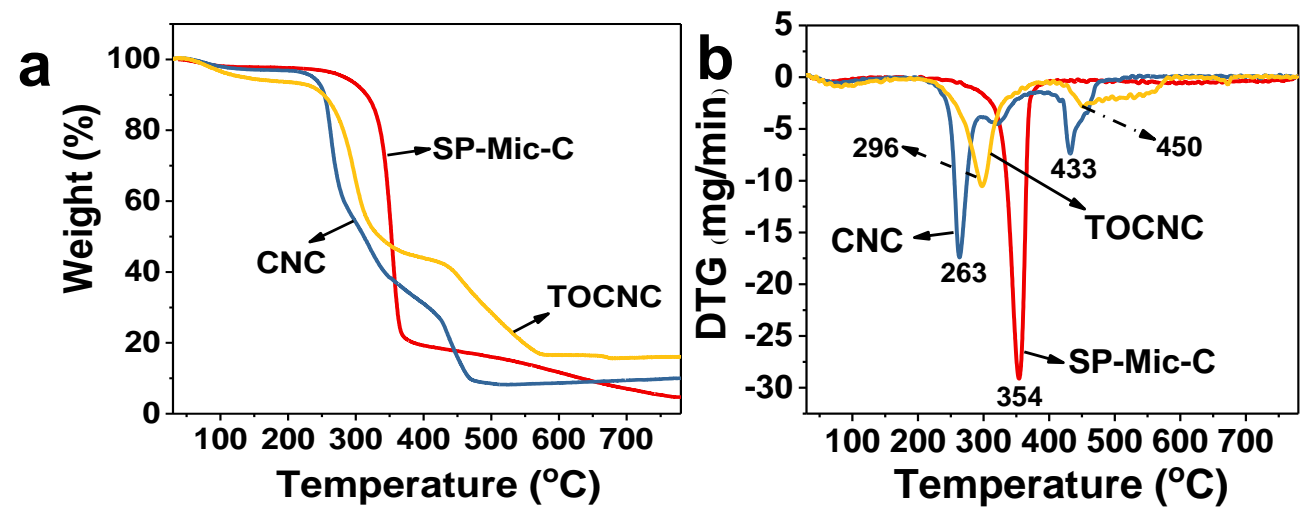

Fig. 7. TG (a) and DTG (b) analysis of SP-Mic-C, CNC, and TOCNC

\section{XPS Analysis}

X-ray photoelectron spectroscopy is one of the technical means for qualitative and quantitative analysis of compounds by photoelectric effect (Zheng et al. 2013). Figure 8 shows the XPS analysis curve of CNC and TOCNC. Table 1 shows the relative content ratio of each element in XPS. It can be seen from Table 1 that both groups of samples were composed of a large amount of $\mathrm{C}, \mathrm{O}$, and a small amount of sulfur and other elements. The oxygen-carbon ratio changed from $30.79 \%$ of CNC to $50.51 \%$ of TOCNC. This showed that the TEMPO-oxidation process increased the oxygen-carbon ratio of the sample. The sulfur content in CNC also decreased from $0.61 \%$ to $0.32 \%$ of TOCNC (Yang et al. 2015), which was attributed to the degradation of cellulose by the alkaline TEMPO/ $\mathrm{NaBr} / \mathrm{NaClO}$ oxidation system. Compared with $\mathrm{CNC}$, the S2P peak of TOCNC was remarkably reduced. The binding energy and chemical shift of the $\mathrm{C} 1 \mathrm{~S}$ peak on the surface of $\mathrm{CNC}$ can explain the change of the sample structure to some extent. Under the influence of electronwithdrawing groups, the density of electron cloud around carbon atom decreases, the shielding effect weakens, and the electron binding energy increases. The three energy spectrum peaks of CNC and TOCNC around $284.8 \mathrm{eV}, 286.5 \mathrm{eV}$, and $288.1 \mathrm{eV}$ correspond to $\mathrm{C}-\mathrm{C} / \mathrm{C}-\mathrm{H}, \mathrm{C}-\mathrm{OH} / \mathrm{C}-\mathrm{O}$, and $\mathrm{C}-\mathrm{O}-\mathrm{C}$, respectively. For TOCNC, a new energy spectral peak 
is generated at $289.06 \mathrm{eV}$, which is the peak of $\mathrm{C}=\mathrm{O}$ in the carboxyl group. Figure $8(\mathrm{a}, \mathrm{d})$ indicates that the oxidation of nanocellulose gave rise to a carboxyl group.
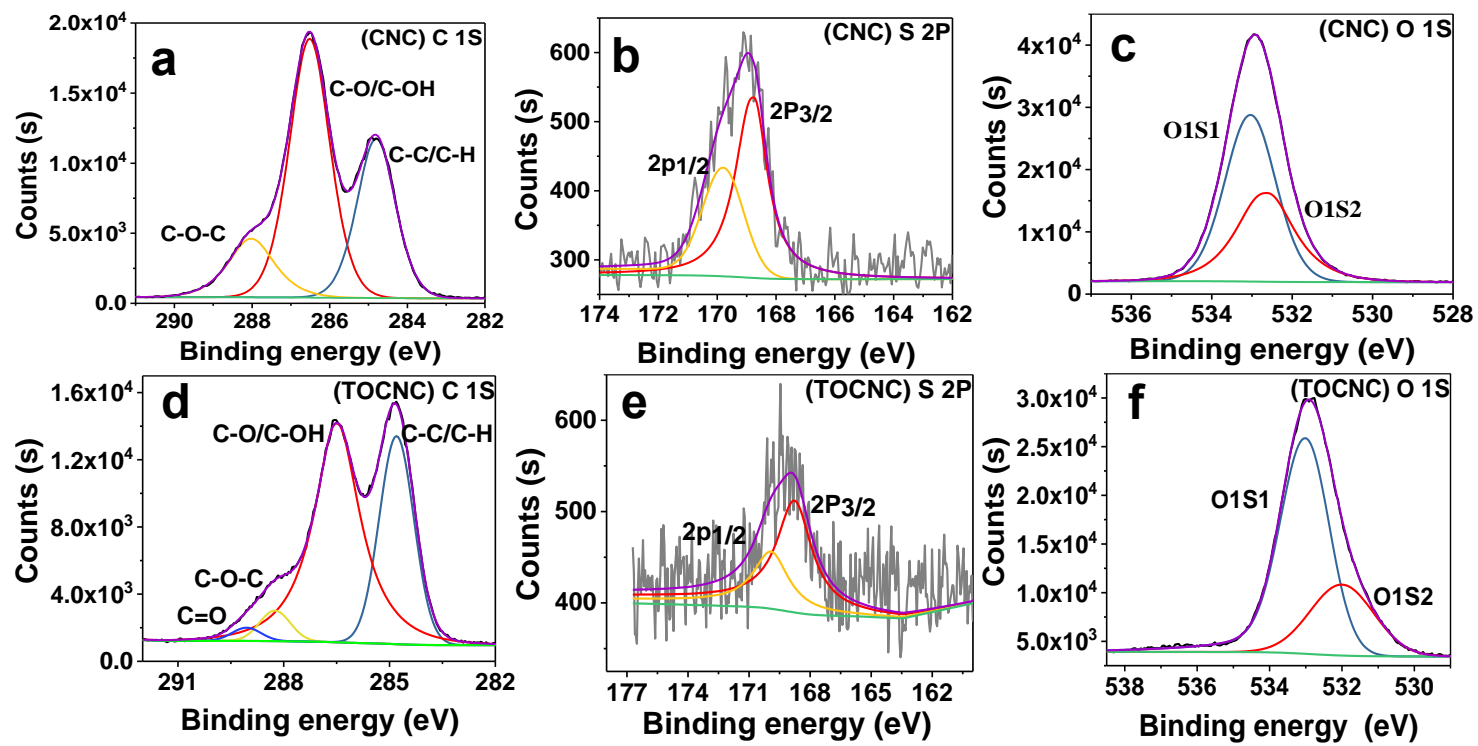

Fig. 8. XPS analysis of CNC (a, b, c) and TOCNC (d, e, f)

Table 1. Comparison Data between CNC and TOCNC

\begin{tabular}{|c|c|c|}
\hline Comparison Type & CNC & TOCNC \\
\hline Yield (\%) & 73.89 & 21.74 \\
\hline Crystallinity (\%) & 70.83 & 26.88 \\
\hline Average Diameter (nm) & 23 & 21 \\
\hline Average Length (nm) & 213 & 165 \\
\hline Temperature of Maximum Thermal Decomposition Rate $\left({ }^{\circ} \mathrm{C}\right)$ & 263 & 296 \\
\hline Relative Oxygen Content in XPS (\%) & 24.54 & 31.46 \\
\hline Relative Carbon Content in XPS (\%) & 74.85 & 68.22 \\
\hline Relative Sulfur Content in XPS (\%) & 0.61 & 0.32 \\
\hline
\end{tabular}

\section{CONCLUSIONS}

1. TEMPO-oxidized-cellulose nanocrystals (TOCNC) with carboxyl functional groups were prepared from Salix psammophila microcrystalline cellulose (SP-Mic-C) by sulfuric acid hydrolysis and 2,2,6,6-tetramethylpiperidin-1-oxyl (TEMPO) oxidation.

2. Cellulose nanocrystals (CNC) and TEMPO-oxidized cellulose nanocrystals (TOCNC) presented short rod fibers, average diameters of $23 \mathrm{~nm}$ and $21 \mathrm{~nm}$, and average lengths of $213 \mathrm{~nm}$ and $165 \mathrm{~nm}$, respectively.

3. The crystallinities of the CNC and TOCNC were $70.8 \%$ and $26.9 \%$, respectively.

4. The successful preparation of TOCNC provides a promising way for the utilization of abandoned agricultural and forestry resources and provides a certain reference for the study of abandoned agricultural and forestry resources. 


\section{ACKNOWLEDGMENTS}

The authors acknowledge support from the Research Start-up Fee for Introducing Talents (RZ1900003332), Inner Mongolia Higher Education Scientific Research Project (NJZY17063), and Inner Mongolia Agricultural University Doctoral Research Start-up Fund (BJ06-57).

\section{REFERENCES CITED}

Bao, Y., and Zhang, G. (2012). "Study of adsorption characteristics of methylene blue onto activated carbon made by Salix psammophila," Energy Procedia 16(1), 11411146. DOI: 10.1016/j.egypro.2012.01.182

Besbes, I., Alila, S., and Boufi, S. (2011). "Nanofibrillated cellulose from TEMPOoxidized eucalyptus fibres: Effect of the carboxyl content," Carbohydrate Polymers 84(3), 975-983. DOI: 10.1016/j.carbpol.2010.12.052

Boccia, A. C., Scavia, G., and Schizzi, I. (2020). "Biobased cryogels from enzymatically oxidized starch: Functionalized materials as carriers of active molecules," Molecules 25(11), 2557. DOI: 10.3390/molecules 25112557

Bragd, P. L., Besemer, A, C., and van, Bekkum. H. (2000). "Bromide-free TEMPOmediated oxidation of primary alcohol groups in starch and methyl $\alpha$-Dglucopyranoside," Carbohydrate Research 328(3), 355-363. DOI: 10.1016/S00086215(00)00109-9

Bragd, P. L., Van, Bekkum. H., and Besemer, A. C. (2004). "TEMPO-mediated oxidation of polysaccharides: Survey of methods and applications," Topics in Catalysis 27(1-4), 49-66. DOI: 10.1023/B:TOCA.0000013540.69309.46

De Castro, D. O., Tabary, N., and Martel, B., (2018). "Controlled release of carvacrol and curcumin: Bio-based food packaging by synergism action of TEMPO-oxidized cellulose nanocrystals and cyclodextrin," Cellulose, 25(2), 1249-1263. DOI: 10.1007/s10570-017-1646-6

Fan, Y., Saito, T., and Isogai, A. (2008). "Chitin nanocrystals prepared by TEMPOmediated oxidation of $\alpha$-chitin” Biomacromolecules 9(1), 192-198.

DOI:10.1021/bm700966g

Hao, J., Wu, F., and Tang, R. (2020). "Preparation of 1,4-linked $\alpha$-D-glucuronans from starch with 4-acetamide-TEMPO/ $\mathrm{NaClO}_{2} / \mathrm{NaClO}$ system," International Journal of Biological Macromolecules 151, 740-746. DOI: 10.1016/j.ijbiomac.2020.02.211

Henriksson, M., Henriksson, G., and Berglund, L. A. (2007). "An environmentally friendly method for enzyme-assisted preparation of microfibrillated cellulose (MFC) nanofibers," European Polymer Journal 43(8), 3434-3441 DOI: 10.1016/j.eurpolymj.2007.05.038

Huang, M.X. (2014). Study on the Preparation Process of Microcrystalline Cellulose From Salix psammophila, Master's Thesis, Zhengzhou University, Zhengzhou, China.

Isogai, A., Saito, T., and Fukuzumi, H. (2011). "TEMPO-oxidized cellulose nanofibers," Nanoscale 3(1), 71-85. DOI: 10.1039/C0NR00583E

Jiang, S., Farooq, A., and Han, F. (2021). "Investigation of a widely applicable process for extracting carboxyl-rich cellulose nanocrystal (CNC)," Fibers and Polymers 2021(3), 1-11. DOI: 10.1007/s12221-021-0279-4 
Ju, S. Y., Yu, H. L., and Ji, L. (2020). "Preparation and characterization of bacterial nanocellulose-based composite membranes," Science of Advanced Materials 12(6), 802-809. DOI: $10.1166 / \mathrm{sam} .2020 .3742$

Kaushik, A., and Singh, M. (2011). "Isolation and characterization of cellulose nanofibrils from wheat straw using steam explosion coupled with high shear homogenization," Carbohydrate Research 346(1), 76-85. DOI: 10.1016/j.carres.2010.10.020

Kumar, R., Kumari, S., and Surah, S. S. (2019). "A simple approach for the isolation of cellulose nanofibers from banana fibers," Materials Research Express 6(10), article no. 105601. DOI: 10.1088/2053-1591/ab3511

Luo, X., and Wang, X. (2017). "Preparation and characterization of nanocellulose fibers from $\mathrm{NaOH} /$ urea pretreatment of oil palm fibers," BioResources 12(3). DOI: 10.15376/biores.12.3.5826-5837

Ma, H., Huang, Q., and Ren, J. (2020). "Structure characteristics, solution properties and morphology of oxidized yeast $\beta$-glucans derived from controlled TEMPO-mediated oxidation," Carbohydrate Polymers 250, 116924. DOI: 10.1016/j.carbpol.2020.116924

Mendoza, D. J., Browne, C., and Raghuwanshi, V. S. (2019). “One-shot TEMPOperiodate oxidation of native cellulose," Carbohydrate Polymers 226, article no. 115292. DOI: 10.1016/j.carbpol.2019.115292

Nguyen, A., and Nguyen, M. N. (2019). "Straw phytolith for less hazardous open burning of paddy straw," Scientific Reports 9(1), article no. 20043. DOI: 10.1038/s41598019-56735-X

Okita, Y., Saito, T., and Isogai, A. (2009). "TEMPO-mediated oxidation of softwood thermomechanical pulp," Holzforschung 63(5), 529-535. DOI: 10.1515/HF.2009.096

Park, N. M., Choi, S., and Oh, J. E. (2019). "Facile extraction of cellulose nanocrystals," Carbohydrate Polymers 223, article no. 115114. DOI: 10.1016/j.carbpol.2019.115114

Ping, L., and Hsieh, Y. L. (2012). "Preparation and characterization of cellulose nanocrystals from rice straw," Carbohydrate Polymers 87(1), 564-573. DOI: 10.1016/j.carbpol.2011.08.022

Rosa, M. F., Medeiros, E. S., and Malmonge, J. A. (2010). "Cellulose nanowhiskers from coconut husk fibers: Effect of preparation conditions on their thermal and morphological behavior," Carbohydrate Polymers 81(1), 83. DOI: 10.1016/j.carbpol.2010.01.059

Saito, T., and Isogai, A. (2004). "TEMPO-mediated oxidation of native cellulose. The effect of oxidation conditions on chemical and crystal structures of the waterinsoluble fractions," Biomacromolecules 5(5), 1983-1989. DOI: 10.1021/bm0497769

Segal, L., Creely, J. J., and Martin, A. E. (1959). "An empirical method for estimating the degree of crystallinity of native cellulose using the X-ray diffractometer," Textile Research Journal 29(10), 786-794. DOI: 10.1177/004051755902901003

Shang, Z., An, X., and Seta, F. T. (2019). "Improving dispersion stability of hydrochloric acid hydrolyzed cellulose nano-crystals," Carbohydrate Polymers 222, article no. 115037. DOI: 10.1016/j.carbpol.2019.115037

Shao, C., Wang, M., and Chang, H. (2017). "A self-healing cellulose nanocrystal-poly (ethylene glycol) nanocomposite hydrogel via Diels-Alder click reaction," ACS Sustainable Chemistry \& Engineering 5(7), 6167-6174. DOI: 10.1021/acssuschemeng.7b01060 
Sun, B., Hou, Q., and Liu, Z. (2015). "Sodium periodate oxidation of cellulose nanocrystal and its application as a paper wet strength additive," Cellulose 22(2), 1135-1146. DOI: $10.1007 / \mathrm{s} 10570-015-0575-5$

Vanderfleet, O. M., Osorio, D. A., and Cranston, E. D. (2018). "Optimization of cellulose nanocrystal length and surface charge density through phosphoric acid hydrolysis," Philosophical Transactions of the Royal Society A: Mathematical, Physical and Engineering Sciences 376(2112), article no. 20170041. DOI: 10.1098/rsta.2017.0041

Yan, L., Wang, L., and Gao, S. (2019). "Celery cellulose hydrogel as carriers for controlled release of short-chain fatty acid by ultrasound," Food Chemistry 309, article no. 125717. DOI: 10.1016/j.foodchem.2019.125717

Yang, D., Peng, X., and Zhong, L. (2015). "Fabrication of a highly elastic nanocomposite hydrogel by surface modification of cellulose nanocrystals," RSC Advances 5(18), 13878-13885. DOI: 10.1039/c4ra10748a

Ye, W., Yokota, S., and Fan, Y. (2021). "A combination of aqueous counter collision and TEMPO-mediated oxidation for doubled carboxyl contents of $\alpha$-chitin nanofibers," Cellulose 1-15. DOI: 10.1007/s10570-021-03676-2

Zheng, G., Cui, Y., and Karabulut, E. (2013). "Nanostructured paper for flexible energy and electronic devices," MRS Bulletin 38(4), 320-325. DOI: 10.1557/mrs.2013.59

Zhong, Y., Wang, K. B., Liu, Y. L., and Wang, X. (2020). "Preparation and characterization of Salix psammophila cellulose and Mic-cellulose under the pretreatment of two kinds of acid," J. Phys. Conf. Ser. 1605(1), article ID 012165. DOI: 10.1088/1742-6596/1605/1/012165

Zhou, L., Wu, H., and Yang, X., (2014). "Selective oxidation of cellulose catalyzed by NHPI/Co(OAc)2 using air as oxidant," Cellulose 21(6), 4059-4065. DOI: 10.1007/s10570-014-0413-1

Article submitted: July 2, 2021; Peer-review completed: December 11, 2021; Revised version received and accepted: December 25, 2021; Published: January 7, 2022. DOI: $10.15376 /$ biores.17.1.1373-1384 